\title{
Acculturation and weight change in Asian-American children: Evidence from the ECLS-
} $\mathrm{K}: 2011$

Cassandra S. Diep, $\mathrm{PhD}^{\mathrm{a}}$

Tom Baranowski, $\mathrm{PhD}^{\mathrm{b}}$

Rachel T. Kimbro, $\mathrm{PhD}^{\mathrm{c}}$

${ }^{a}$ Department of Health Disparities Research, The University of Texas MD Anderson Cancer Center, Houston, TX, USA

'USDA/ARS Children's Nutrition Research Center, Department of Pediatrics, Baylor College of Medicine, Houston, TX, USA

${ }^{c}$ Department of Sociology, Rice University, Houston, TX, USA

Corresponding author:

Cassandra S. Diep, PhD

Department of Health Disparities Research - Unit 1440

UT MD Anderson Cancer Center

P.O. Box 301402

Houston, TX 77230-1402 USA

Telephone: +17137945007

Fax: +1 7137921152

E-mail: CSYeung@mdanderson.org

Word counts: 3,499 (main text, excluding tables, figure, and references) / 250 (abstract) 


\begin{abstract}
(250/250)
Despite relatively low rates of overweight and obesity among Asian-American children, disparities exist based on acculturation, socioeconomic status, and Asian ethnicity. The purpose of this study was to examine the association between acculturation and weight change in AsianAmerican children. Secondary aims were to compare changes by Asian ethnic group and acculturation x socioeconomic status. Participants included 1,200 Asian-American children from the Early Childhood Longitudinal Study, Kindergarten Class of 2010-11, a longitudinal study of U.S. children attending kindergarten in 2010-2011. Multinomial logistic regressions were conducted to predict weight change based on body mass indices in kindergarten (spring 2011) and second grade (spring 2013): consistently healthy weight, consistently overweight/obese, healthy weight change, and unhealthy weight change. Models included demographic, household, socioeconomic status, and acculturation measures, specifically mother's English proficiency and percentage of life spent in the U.S. Overall, $72.3 \%$ of children were at healthy weights in kindergarten and second grade. Of all Asian ethnic groups, Filipino children had the highest rate of being consistently overweight/obese (24.8\%) and the lowest rate of being consistently healthy weight $(62.9 \%)$. In addition, mother's English proficiency predicted unhealthy weight change (OR: 0.83; 95\% CI: 0.75-0.92) and healthy weight change (OR: 0.75; 95\% CI: 0.65-0.86), relative to "consistently healthy weight." English proficiency also predicted being consistently overweight/obese for children with less educated mothers. Findings enhance our understanding of obesity disparities within Asian Americans and highlight the need to disaggregate the population. Obesity interventions are needed for Filipino children and families with low socioeconomic status but high English proficiency.
\end{abstract}

Keywords: acculturation, Asian, child, ethnicity, longitudinal, overweight and obesity 


\section{Introduction}

Childhood overweight and obesity is a major problem in the United States (U.S.).

Although obesity prevalence in youth has been stable over the past decade, ${ }^{1}$ rates have significantly increased since 1999, ${ }^{2}$ and overweight and obesity rates remain high. ${ }^{2,3}$ From 2011 to $2012,31.8 \%$ of children and adolescents were overweight or obese (OW/OB), and $16.9 \%$ were obese. ${ }^{1}$ Being OW/OB as a child may predict obesity in adulthood. ${ }^{4,5}$

Ethnic-immigrant groups, including Asians, experience disparities in obesity. ${ }^{6}$ Asians constitute the fastest-growing racial/ethnic group in the U.S., growing by $29.8 \%$ from 2009 (5.1\% of the U.S. population) to 2015 (6.4\% of the U.S. population). ${ }^{7}$ When considered overall, Asian-American children have lower overweight and obesity prevalence than other racial/ethnic groups. ${ }^{1,3}$ In one study, $26.3 \%$ of 4-year-old Asian-American children were OW/OB, as compared to $36.0 \%$ of white children. ${ }^{8}$ However, there were differences in overweight/obesity rates based on Asian ethnicity: 15.6\% of Asian Indians versus 34.7\% of Vietnamese children. In addition, the obesity risk for Asian-American children from foreign-born mothers may be half that of Asian-American children from U.S.-born mothers. ${ }^{8}$

One possible reason for differences in obesity risk is acculturation, or the process by which individuals from one culture adopt to another culture. ${ }^{9}$ Acculturation may be positively related to obesity and obesogenic behaviors, including increased body mass index (BMI), preference for Western foods, and increased intake of omega- 6 fatty acids. ${ }^{10-13}$ However, research with children has been mixed, at least among Latinos. ${ }^{14}$ In addition, most studies investigating acculturation and weight status have been cross-sectional. ${ }^{10}$ Few studies have explored the relationship longitudinally. One longitudinal study of Asian, Hispanic, and nonHispanic white early adolescent females found no association between overweight status and acculturation over time, ${ }^{15}$ whereas another study of immigrant women from the former Soviet Union found an inverse correlation between acculturation and BMI change over 10 years. ${ }^{16}$ Other studies have found positive relationships between acculturation and weight status longitudinally. ${ }^{17,18}$ Sons of black, Asian, or Hispanic immigrants who moved to the U.S. as adults were heavier and gained more weight than sons of U.S. natives, and sons gained weight faster if their parents were English-proficient. ${ }^{17}$

As an additional confounder, the relationship between acculturation and weight status is complicated by socioeconomic status (SES). ${ }^{19}$ SES and acculturation are interconnected, such 
that SES may modify the relationship between acculturation and obesity. For example, lower acculturation may be protective against poor health outcomes for lower SES individuals. In addition, while acculturation is related to obesity, SES is also independently related to obesity. ${ }^{20}$ A study of Chinese-American children found higher SES children to have more westernized dietary behaviors, ${ }^{21}$ which may lead to obesity and other diseases. ${ }^{22}$ Few studies have disentangled the SES-acculturation relationship in relation to obesity and health outcomes.

The long-term relationship between acculturation and weight status in children remains unclear. More research is needed, especially among Asians, who have experienced both acculturation and increased childhood obesity. ${ }^{11,13}$ The availability of kindergarten and second grade anthropometric data from the U.S.'s Early Childhood Longitudinal Study, Kindergarten Class of 2010-11 (ECLS-K:2011) ${ }^{23}$ provided an opportunity to evaluate the relationship between acculturation and BMI change during the early school years, when there may be excess BMI gains. $^{24}$ The purpose of the current study was to examine the association between acculturation and BMI change in a sample of Asian-American children. We hypothesized increases in BMI with acculturation (i.e., transition to $\mathrm{OW} / \mathrm{OB}$ ), given that acculturation has been identified as a childhood obesity risk factor. ${ }^{13}$ Secondary aims were to compare changes by Asian ethnic group and examine interactions between acculturation and SES.

\section{Methods}

\section{$\underline{\text { Data and sample }}$}

We used data from the ECLS-K:2011, a nationally-representative, longitudinal study of U.S. children attending kindergarten in 2010-2011. ${ }^{23}$ Sponsored by the National Center for Education Statistics, ECLS-K:2011 used a multistage sampling design to sample and follow a cohort of approximately 18,200 children from the fall of kindergarten (fall 2010) to the spring of fifth grade (spring 2016). Trained field staff conducted child assessments (e.g., cognitive assessments, height and weight measurements) and parent interviews (e.g., family characteristics), while teachers, school administrators, and care providers completed selfadministered questionnaires. More details about data collection procedures are provided by Mulligan and colleagues. ${ }^{23}$ The student and parent response rates were $87 \%$ and $74 \%$, respectively, for the first data collection. 
For this study, we used data from the spring of kindergarten (when acculturation was measured) and spring of second grade (the most recent wave of available data at the time of study). Participants were excluded if they were missing a child assessment and/or parent interview at either wave. Only children who were of Asian descent with at least one foreignborn parent were included in our analyses. Missing data for the rest of our covariates were multiply imputed for five complete datasets. The final sample size comprised 1,200 children (rounded to the nearest 50, per our restricted data user agreement). Rice University's Institutional Review Board determined this study to be exempt.

\section{$\underline{\text { Measures }}$}

\section{Anthropometrics}

Based on height and weight, we calculated BMI and classified each child as healthy weight (HW) $(\mathrm{BMI}<85$ th percentile), overweight (BMI $\geq 85$ th and $<95$ th percentile), or obese (BMI $\geq 95$ th percentile). ${ }^{25}$ Using kindergarten and second grade data points, four weight change groups were created: 1) consistently $\mathrm{HW}, 2$ ) consistently $\mathrm{OW} / \mathrm{OB}, 3$ ) healthy weight change (i.e., OW/OB to HW), and 4) unhealthy weight change (i.e., HW to OW/OB). ${ }^{26}$ In our models, we controlled for the months elapsed between the spring of kindergarten and spring of second grade waves, to ensure different interview times across children did not influence weight change categories.

\section{Demographics, household factors, and SES}

Demographic variables included child age and sex, obtained during the child assessment and confirmed by parents during parent interviews. Mother's age was obtained from parent interviews. Asian ethnicity was also ascertained from parent interviews; children were classified as Chinese (both parents born in China, Hong Kong, or Taiwan), South Asian (both parents born in India, Pakistan, Bangladesh, Sri Lanka, Nepal, or Bhutan), Vietnamese (both parents born in Vietnam), Filipino (both parents born in the Philippines), or other (both parents born in another Asian country, children with one Asian-born parent and one U.S.-born parent, or children with mixed Asian ancestry). The sub-categories in "other" were too small to analyze individually. Ages were based on the spring of second grade wave; the other demographic variables came from the spring of kindergarten. 
Family household and SES measures were obtained from parent interviews. These measures included highest level of education for the child's mother (no high school degree or high school degree), family structure (living with two biological parents or not), and number of siblings in the household. In addition, poverty status was measured using federal poverty level (FPL) threshold status of the household, based on income-to-poverty ratios. Families were categorized as being $200 \%$ or above FPL, $100-200 \%$ FPL, or below 100\% FPL.

\section{Acculturation}

Mother's acculturation was determined using questions from parent interviews in the spring of kindergarten: mother's English proficiency and percentage of mother's life spent in the U.S. Language and residence measures have been frequently used as proxy measures of acculturation, and correlate with various acculturation scales $(\mathrm{r}=.17-.76) .{ }^{27}$ In this study, the language and residence measures were correlated at 23 .

English proficiency was assessed using four questions measuring how well the mother spoke, read, wrote, and understood someone speaking English ( $\alpha=.97)$. Each question was coded on a four-point scale from 1 (very well) to 4 (not well at all). We then reverse-coded and summed the items, so that higher scores represented better English proficiency (range: 4-16).

Percentage of mother's life spent in the U.S. was calculated based on 1) mother's current age and 2) age when she first moved to the U.S. (i.e., age at arrival). We subtracted the age at arrival from her current age, and divided the difference by her current age. Larger values represented a higher percentage of the mother's life spent in the U.S.

\section{$\underline{\text { Statistical analyses }}$}

We utilized multinomial logistic regression to predict weight change, with "consistently HW" as the reference category. Chinese children served as the comparison group because they are the largest Asian ethnic group in the U.S. ${ }^{7}$ and were the reference group in multiple studies of Asian-American childhood obesity. ${ }^{8,28}$ The first model included ethnicity, child's age, sex, household, and SES factors. The second model added the acculturation measures. Although we tested models with each acculturation measure entered separately, results when both were simultaneously included did not differ substantively, so we presented the model with both. Percentage of mother's life spent in the U.S. was normally distributed, while English proficiency 
was not (i.e., approximately $40 \%$ of mothers scored the maximum of 16). The final model added acculturation x SES interaction terms. We also tested interactions between Asian ethnicity and each acculturation measure, but found no evidence that acculturation processes operated differently by ethnicity and thus did not include those results. Finally, we generated predicted probabilities, with adjustments for all covariates, to illustrate the overall probability of weight change by acculturation x SES. All analyses were conducted using STATA/SE (Version 14.0, 2015, StataCorp LP, College Station, Texas, USA), with statistical significance defined as p<.05.

\section{Results}

Demographic, household, and acculturation characteristics

Table 1 presents descriptive statistics for the full sample $(n=1,200)$ and by Asian ethnicity. Overall, children were about equal boys and girls. Filipino mothers and children were the oldest (39.1 years and 97.2 months, respectively). Rates of living with two biological parents were high across the sample (87.9-97.5\%), with the highest rate among South Asian children and lowest among Vietnamese children. South Asian children also had the highest rate of living in higher SES households: $75.2 \%$ had an income-to-poverty ratio above $200 \%$ FPL and $84.0 \%$ had mothers with greater than a high school degree. Vietnamese children had the lowest rate of living in higher SES households.

[Insert Table 1 here]

In terms of acculturation, Filipino mothers had the highest mean English proficiency score of 14.3, followed by South Asian and "other ethnicity" mothers. "Other ethnicity" mothers had the highest mean percentage of life spent in the U.S. (47.5\%).

\section{Weight change categories}

Overall, $72.3 \%$ of children were HW in kindergarten and in second grade (see Table 1). By contrast, 16.5\% were OW/OB at both time points, $7.8 \%$ had an unhealthy weight change from $\mathrm{HW}$ to $\mathrm{OW} / \mathrm{OB}$, and $3.4 \%$ transitioned from OW/OB to $\mathrm{HW}$. Filipino children had the highest rate of being consistently OW/OB (24.8\%) and lowest rate of being consistently HW $(62.9 \%)$. In contrast, Chinese children had the lowest rate of being consistently OW/OB and 
highest rate of being consistently HW, confirming their use as the comparison group in our multinomial logistic regressions for predicting weight change.

Models 1a-3a in Table 2 presents odds ratios (ORs) and 95\% confidence intervals from multinomial logistic regression models predicting the "consistently OW/OB" category, with "consistently HW" as the reference category. With all covariates included, Filipino children (when compared to Chinese children) had higher odds of being in the "consistently OW/OB" category than "consistently HW," as did older children (model 2a). Acculturation was not a significant predictor until model 3a, when the interaction term between English proficiency and mother's education was added. Specifically, for children whose mothers lacked a high school degree, the likelihood of the child being "consistently OW/OB" increased as mother's English proficiency increased, but not as much for children whose mothers had a high school degree (Figure 1). Similarly, the probability of being "consistently HW" increased with English proficiency, but only for children whose mothers had a high school degree. An interaction between mother's English proficiency and poverty status operated in the same way (results available upon request). There were no significant interactions for percentage of mother's life spent in the U.S and either SES measure.

[Insert Table 2 here]

[Insert Figure 1 here]

Regarding weight change, there were no ethnic, household, or SES differences in the odds of being in the "unhealthy weight change" or "healthy weight change" group (Table 2, models $2 \mathrm{~b}$ and $2 \mathrm{c}$ ), relative to the "consistently HW" group. However, child's sex and age predicted unhealthy weight change, so that boys and older children had higher odds of being in the "unhealthy weight change" group. In addition, mothers with greater English proficiency had children with lower odds of being in the "unhealthy weight change" (model 2b) and "healthy weight change" (model 2c) groups, relative to "consistently HW" group. Unlike for the "consistently OW/OB" group, there were no acculturation x SES interactions for the weight change groups (models $3 b$ and $3 c$ ), meaning that increased English proficiency decreased the probability of unhealthy or healthy weight change, regardless of mother's education (Figure 1). 


\section{Discussion}

To our knowledge, the current study was the first to examine acculturation and BMI change, as well as ethnicity and BMI change, in Asian-American children. Overall, most children were HW in kindergarten and second grade; only $27.7 \%$ of children were OW/OB in kindergarten and/or second grade. This finding is consistent with data from the ECLS, Birth Cohort: $26.3 \%$ of 4-year-old Asian-American children were OW/OB. ${ }^{8}$ Another study reported lower rates of $9.0 \%$ and $19.9 \%$ in children aged 2-5 and 6-11 years, respectively, ${ }^{1}$ but this study was cross-sectional and may mask changes in overweight and obesity over time. A longitudinal study found higher rates of overweight and obesity: only $59.8 \%$ were persistently non-OW/OB from kindergarten to fifth grade, whereas $15.2 \%$ were chronically OW/OB, $9.6 \%$ were late-onset OW/OB, $8.8 \%$ were early-onset OW/OB, and $6.7 \%$ became $\mathrm{HW} .{ }^{29}$ However, this study covered a longer age period and sampled children from southeast Texas, so the rates may not reflect Asian-American children nationally, especially given higher rates of overweight and obesity in Texas than the U.S. ${ }^{30}$ More research is needed to understand weight change in this population, in order to identify points for intervention. A comprehensive approach should target causes of weight change year-round, with particular emphasis in the summer, when Asian children may be more likely to increase their weight status. ${ }^{31,32}$

In addition, overweight and obesity prevalence differed between Asian ethnic groups, with Filipino children having the highest odds of being OW/OB in both kindergarten and second grade. These findings partly corroborate another study that found Filipino, Southeast Asian, and mixed Asian ethnicity adolescents to be more likely to be overweight than Chinese adolescents, ${ }^{28}$ whereas another study found Vietnamese children to be at highest risk. ${ }^{8}$ These studies had relatively small numbers of children representing the different Asian ethnic groups (e.g., 100 Filipinos in the current study), so replication is needed in larger samples to draw strong conclusions about which groups are most at risk. Despite small samples and different findings, all these studies support the heterogeneity in obesity rates within Asians and highlight the need for disaggregated research. ${ }^{33}$ Combining all Asians misrepresents the risks experienced by particular groups, given their differences in SES, immigration histories, access to resources, and beliefs/practices. ${ }^{34}$ Interventions may need to be culturally-tailored for each group, although more research is needed in this area. There have been limited obesity interventions for Asian- 
American children, and most have targeted Chinese-American children, ${ }^{35-39}$ so efforts are needed to identify strategies for obesity intervention in Filipino and other at-risk Asian populations.

This study also found acculturation, specifically mother's English proficiency, to be a significant predictor of weight change. The odds of weight change, whether unhealthy or healthy, relative to staying HW, were less in children of more English proficient mothers. In other words, children of more English proficient, or acculturated, mothers were more likely to be HW in both kindergarten and second grade, than to improve or worsen their weight status, which was an unexpected finding. Given previous research demonstrating a positive relationship between acculturation and overweight/obesity, ${ }^{10}$ we expected acculturation to be related to unhealthy weight change in our sample. However, our findings corroborate some studies that found a negative association between parental acculturation and Asian-American children's weight status. ${ }^{40-43}$ Unfortunately, all these studies were cross-sectional and conducted by one research group using similar samples, making interpretation and comparison difficult. Longitudinal research has resulted in mixed findings, ${ }^{15-18}$ so more research is needed.

Relatedly, many acculturation-related studies have focused on diet, demonstrating less healthful dietary behaviors (and therefore obesity) with greater acculturation. ${ }^{44-46}$ In contrast, it is also possible that greater acculturation may lead to more healthful behaviors, such as mothers with higher English proficiency having higher healthcare utilization ${ }^{47}$ or quality of healthcare. $^{48}$ These avenues may potentially offset dietary changes and lead to lower obesity with acculturation. More research is needed to investigate other avenues through which acculturation may influence health.

Mother's English proficiency also increased the probability of a child being consistently $\mathrm{OW} / \mathrm{OB}$, but more so for children whose mothers had low education. This finding demonstrates the interconnectedness of acculturation and SES, so that lower levels of acculturation may be protective against BMI growth and negative health outcomes for economically disadvantaged groups, perhaps through healthier food intake patterns, retention of social norms, and social support. ${ }^{19,49}$ Multiple assimilation theories recognize that acculturation may vary based on social and economic contexts of reception, such that groups may acculturate into different social strata (e.g., the relatively healthy lifestyle of high SES or relatively unhealthy lifestyle of low SES). ${ }^{49}$ More research is needed to investigate the SES-acculturation relationship in relation to obesity and health outcomes, in order to better identify intervention targets, because acculturation's 
impact on health outcomes and behaviors may depend on SES and other factors. Interventions to prevent consistent overweight/obesity may need to focus on families with low SES but high English proficiency, while interventions to prevent weight gain should focus on families with high English proficiency, regardless of SES.

Overall, we found household measures to not be related to weight change. In other studies, children with single mothers or no siblings were more likely to be obese or have larger BMI increases, ${ }^{50-54}$ as were children in families headed by cohabiting biological or step-parents or a relative. ${ }^{53,54}$ However, these studies included diverse samples, not just Asians. One study of Asian-American families found little evidence of family structure influencing self-rated health and psychological distress, ${ }^{55}$ so more research is needed to understand family structure in Asians. It is also possible that there was little diversity in family structure in our sample (i.e., $92.2 \%$ lived with two biological parents and the average number of siblings was 1.1) to adequately investigate the relationship between family structure and overweight/obesity.

\section{Study limitations and strengths}

This study's strengths include the longitudinal design, large nationally-representative sample of Asian Americans, objectively-measured height and weight, and disaggregation of Asian Americans. Despite contributing to limited research on acculturation, ethnicity, and weight change in Asian-American children, this study had several limitations. First, we used mother's acculturation level, with English proficiency and percentage of life spent in the U.S. as proxy measures. Mother's acculturation may not correspond to child's acculturation, and child's acculturation may be exaggerated by father's acculturation. Although other studies have used maternal acculturation to investigate childhood obesity, ${ }^{11,13}$ findings may differ if paternal or child acculturation was used. In addition, proxy measures may not fully capture acculturation. Different measures across studies may yield different, difficult-to-compare findings. ${ }^{56}$ As exemplified in this study, English proficiency was a significant predictor of weight change, while percentage of life spent in the U.S. was not. The correlation between the two acculturation measures was .23, essentially due to the heterogeneity of the Asian sample: some mothers had high English proficiency but little time in the U.S. and vice versa. It is also possible that the two acculturation measures assess different things: language proficiency may measure access to health information and services, rather than cultural adaptation or change. ${ }^{27}$ Findings should be 
interpreted in the context of the acculturation measure. Relatedly, because there were few children of U.S.-born parents in the ECLS-K:2011 dataset, and because the acculturation measures may not apply in the same way to this group, we limited analyses to children of at least one foreign-born parent and were unable to include generation status in analyses. As another limitation, one measure of SES was mother's highest level of education. We were unable to standardize education, given the likelihood that degrees were obtained from a variety of countries with different educational systems and standards, so we chose a dichotomous category to minimize differences across schooling systems. Next, we used BMI to measure overweight and obesity, which may underestimate obesity-related risks. ${ }^{57}$ Especially in Asian populations, there may be elevated risks of adiposity and obesity-related diseases at lower BMI levels. ${ }^{58,59}$ Lastly, findings from this study may not be generalizable to Asian children in other countries.

\section{Conclusion}

The present study contributes to acculturation, ethnicity, and weight change research among Asian-American children. First, Filipino children had the highest overweight and obesity risk in kindergarten and second grade, which enhance our understanding of Asian-American childhood obesity and disparities. Second, acculturation (specifically mother's English proficiency), but not household or SES measures, was a significant predictor of weight change in unexpected directions, suggesting that mother's acculturation may be related to a child being consistently HW. With the acculturation x SES interaction term, mother's English proficiency was also a significant predictor of being consistently OW/OB, so that children from less educated households were at greater risk of being consistently OW/OB with acculturation, than children from more educated households. Research is needed to verify these findings and use more comprehensive acculturation and obesity measures.

\section{Conflict of Interest Statement}

All authors have no conflict of interest to declare.

\section{Acknowledgements}

The authors would like to thank all the investigators, staff, and participants of the ECLSK:2011 for their valuable contributions. This study did not receive any specific grant from 
funding agencies in the public, commercial, or not-for-profit sectors. Tom Baranowski was funded in part with federal funds from the USDA/ARS under Cooperative Agreement No. 586250-0-008. 


\section{References}

1. Ogden CL, Carroll MD, Kit BK, Flegal KM. Prevalence of childhood and adult obesity in the United States, 2011-2012. JAMA. 2014;311:806-814.

2. Skinner AC, Perrin EM, Skelton JA. Prevalence of obesity and severe obesity in US children, 1999-2014. Obesity (Silver Spring). 2016;24:1116-1123.

3. Ogden CL, Carroll MD, Lawman HG, et al. Trends in obesity prevalence among children and adolescents in the United States, 1988-1994 through 2013-2014. JAMA. 2016;315:2292-2299.

4. Guo SS, Wu W, Chumlea WC, Roche AF. Predicting overweight and obesity in adulthood from body mass index values in childhood and adolescence. Am J Clin Nutr. 2002;76:653-658.

5. Whitaker RC, Wright JA, Pepe MS, Seidel KD, Dietz WH. Predicting obesity in young adulthood from childhood and parental obesity. N Engl J Med. 1997;337:869-873.

6. Singh GK, Siahpush M, Hiatt RA, Timsina LR. Dramatic increases in obesity and overweight prevalence and body mass index among ethnic-immigrant and social class groups in the United States, 1976-2008. J Community Health. 2011;36:94-110.

7. U.S. Census Bureau. Selected Population Profile in the United States: American Community Survey 1-Year Estimates. http://factfinder.census.gov/. Accessed December $12,2016$.

8. Jain A, Mitchell S, Chirumamilla R, et al. Prevalence of obesity among young AsianAmerican children. Child Obes. 2012;8:518-525.

9. Berry JW. Immigration, acculturation, and adaptation. Applied Psychology. 1997;46:534.

10. Delavari M, Sønderlund AL, Swinburn B, Mellor D, Renzaho A. Acculturation and obesity among migrant populations in high income countries - A systematic review. BMC Public Health. 2013;13:458.

11. Diep CS, Foster MJ, McKyer ELJ, Goodson P, Guidry JJ, Liew J. What are AsianAmerican youth consuming? A systematic literature review. J Immigr Minor Health. 2015;17:591-604. 
12. Diep CS, Lemaitre RN, Chen TA, et al. Acculturation and plasma fatty acid concentrations in Hispanic and Chinese-American adults: The Multi-Ethnic Study of Atherosclerosis. PLoS One. 2016;11:e0149267.

13. Lu W, Diep CS, McKyer ELJ. Risk factors for childhood obesity among Asian Americans: A systematic review of literature and recommendations for health care research. J Health Care Poor Underserved. 2015;26:171-190.

14. McLeod DL, Buscemi J, Bohnert AM. Becoming American, becoming obese? A systematic review of acculturation and weight among Latino youth. Obes Rev. 2016;17: 1040-1049.

15. Fialkowski MK, Ettienne R, Shvetsov YB, et al. Ethnicity and acculturation: Do they predict weight status in a longitudinal study among Asian, Hispanic, and non-Hispanic White early adolescent females? Adolesc Health Med Ther. 2015;6:1-7.

16. Miller AM, Chandler PJ, Wilbur J, Sorokin O. Acculturation and cardiovascular disease risk in midlife immigrant women from the former Soviet Union. Prog Cardiovasc Nurs. 2004;19:47-55.

17. van Hook J, Baker E. Big boys and little girls: Gender, acculturation, and weight among young children of immigrants. J Health Soc Behav. 2010;51:200-21.

18. Erber Oakkar E, Stevens J, Bradshaw PT, et al. Longitudinal study of acculturation and BMI change among Asian American men. Prev Med. 2015;73:15-21.

19. Fitzgerald N. Acculturation, economic status, and health among Hispanics. NAPA Bull. 2010;34:28-46.

20. McLaren L. Socioeconomic status and obesity. Epidemiol Rev. 2007;29:29-48.

21. Diep CS, Leung R, Thompson D, Gor BJ, Baranowski T. Culture and diet among Chinese American children aged 9-13 years: A qualitative study [published online ahead of print December 24, 2016]. J Nutr Educ Behav. doi: 10.1016/j.jneb.2016.11.002.

22. Myles IA. Fast food fever: Reviewing the impacts of the Western diet on immunity. Nutr J. 2014;13:61.

23. Mulligan GM, Hastedt S, McCarroll JC. First-time kindergartners in 2010-11: First findings from the kindergarten rounds of the Early Childhood Longitudinal Study, Kindergarten Class of 2010-11 (ECLS-K:2011). Washington, DC: National Center for Education Statistics;2012. 
24. Datar A, Shier V, Sturm R. Changes in body mass during elementary and middle school in a national cohort of kindergarteners. Pediatrics. 2011;128:e1411-e1417.

25. Kuczmarski RJ, Ogden CL, Guo SS, et al. 2000 CDC growth charts for the United States: Methods and development. Vital Health Stat 11. 2002:1-190.

26. Chang Y, Halgunseth LC. The association between family meals and early-adolescents' weight status change in the context of parental discipline practices: The moderating roles of ethnicity and acculturation. J Immigr Minor Health. 2015;17:450-458.

27. Thomson MD, Hoffman-Goetz L. Defining and measuring acculturation: A systematic review of public health studies with Hispanic populations in the United States. Soc Sci Med. 2009;69:983-991.

28. Cook WK, Tseng W, Bautista R, John I. Ethnicity, socioeconomic status, and overweight in Asian American adolescents. Prev Med Rep. 2016;4:233-237.

29. Chen TA, Baranowski T, Moreno JP, et al. Obesity status trajectory groups among elementary school children. BMC Public Health. 2016;16:526.

30. Singh GK, Kogan MD, van Dyck PC. Changes in state-specific childhood obesity and overweight prevalence in the United States from 2003 to 2007. Arch Pediatr Adolesc Med. 2010;164:598-607.

31. Chen TA, Baranowski T, Moreno JP, et al. Obesity status transitions across the elementary years: Use of Markov chain modelling. Pediatr Obes. 2016;11:88-94.

32. Moreno JP, Johnston CA, Chen TA, et al. Seasonal variability in weight change during elementary school. Obesity (Silver Spring). 2015;23:422-428.

33. Islam NS, Khan S, Kwon S, Jang D, Ro M, Trinh-Shevrin C. Methodological issues in the collection, analysis, and reporting of granular data in Asian American populations: Historical challenges and potential solutions. J Health Care Poor Underserved. 2010;21:1354-1381.

34. Yi SS, Kwon SC, Wyatt L, Islam N, Trinh-Shevrin C. Weighing in on the hidden Asian American obesity epidemic. Prev Med. 2015;73:6-9.

35. Chen JL, Kwan M, Mac A, Chin NC, Liu K. iStart smart: A primary-care based and community partnered childhood obesity management program for Chinese-American children: Feasibility study. J Immigr Minor Health. 2013;15:1125-1128. 
36. Chen JL, Weiss S, Heyman MB, Cooper B, Lustig RH. The efficacy of the web-based childhood obesity prevention program in Chinese American adolescents (Web ABC study). J Adolesc Health. 2011;49:148-154.

37. Chen JL, Weiss S, Heyman MB, Lustig RH. Efficacy of a child-centred and family-based program in promoting healthy weight and healthy behaviors in Chinese American children: A randomized controlled study. J Public Health (Oxf). 2010;32:219-229.

38. Chen J-L, Weiss S, Heyman MB, Vittinghoff E, Lustig R. Pilot study of an individually tailored educational program by mail to promote healthy weight in Chinese American children. J Spec Pediatr Nurs. 2008;13:212-222.

39. Chen JL, Kwan M, Liu K, Yu F. The feasibility and efficacy of healthy weight management program for low income Chinese American overweight and obese children in a primary care clinic. J Pediatr Nurs. 2015;30:821-828.

40. Chen JL, Kennedy C. Factors associated with obesity in Chinese-American children. Pediatr Nurs. 2005;31:110-115.

41. Chen JL, Weiss S, Heyman MB, Lustig R. Risk factors for obesity and high blood pressure in Chinese American children: Maternal acculturation and children's food choices. J Immigr Minor Health. 2011;13:268-275.

42. Chen JL, Wu Y. Cardiovascular risk factors in Chinese American children: Associations between overweight, acculturation, and physical activity. J Pediatr Health Care. 2008;22:103-110.

43. Chen JL, Wilkosz ME. Self-competence and quality of life in Chinese American children. Calif J Health Promot. 2009;7:67-77.

44. Ayala GX, Baquero B, Klinger S. A systematic review of the relationship between acculturation and diet among Latinos in the United States: Implications for future research. J Am Diet Assoc. 2008;108:1330-1344.

45. Satia-Abouta J, Patterson RE, Neuhouser ML, Elder J. Dietary acculturation: Applications to nutrition research and dietetics. J Am Diet Assoc. 2002;102:1105-1118.

46. Pérez-Escamilla R, Putnik P. The role of acculturation in nutrition, lifestyle, and incidence of type 2 diabetes among Latinos. J Nutr. 2007;137:860-870. 
47. Bermudez-Parsai M, Mullins Geiger JL, Marsiglia FF, Coonrod DV. Acculturation and health care utilization among Mexican heritage women in the United States. Matern Child Health J. 2012;16:1173-1179.

48. Becerra D, Androff D, Messing JT, Castillo J, Cimino A. Linguistic Acculturation and perceptions of quality, access, and discrimination in health care among Latinos in the United States. Soc Work Health Care. 2015;54:134-157.

49. Van Hook J, Stamper Balistreri K. Immigrant generation, socioeconomic status, and economic development of countries of origin: A longitudinal study of body mass index among children. Soc Sci Med. 2007;65:976-989.

50. Chen AY, Escarce JJ. Family structure and childhood obesity, Early Childhood Longitudinal Study - Kindergarten Cohort. Prev Chronic Dis. 2010;7:A50.

51. Chen AY, Escarce JJ. Family structure and childhood obesity: An analysis through 8th grade. Matern Child Health J. 2014;18:1772-1777.

52. Schmeer KK. Family structure and obesity in early childhood. Soc Sci Res. 2012;41:820832.

53. Augustine JMK, Rachel T. Associations and intervening mechanisms between family structure and young children's obesity [published online ahead of print December 23, 2015]. J Fam Issues. doi: 10.1177/0192513X15621344.

54. Augustine JMK, Rachel T. Family structure and obesity among U.S. children. J Appl Res Child. 2013;4:1-24.

55. Walton E, Takeuchi DT. Family structure, family processes, and well-being among Asian Americans: Considering gender and nativity. J Fam Issues. 2010;31:301-332.

56. Demes KA, Geeraert N. Measures matter: Adaptation, cultural distance, and acculturation orientation revisited. J Cross Cult Psychol. 2014;45:91-109.

57. Rothman KJ. BMI-related errors in the measurement of obesity. Int J Obes. 2008;32:S56S59.

58. Hsu WC, Araneta MRG, Kanaya AM, Chiang JL, Fujimoto W. BMI cut points to identify at-risk Asian Americans for type 2 diabetes screening. Diabetes Care. 2015;38:150-158.

59. WHO Expert Consultation. Appropriate body-mass index for Asian populations and its implications for policy and intervention strategies. Lancet. 2004;363:157-163. 
Table 1. Demographic, household, acculturation, and weight characteristics for the full sample and by ethnicity, $\mathrm{n}=1,200$ AsianAmerican children of foreign-born mothers, ECLS-K:2011

\begin{tabular}{|c|c|c|c|c|c|c|}
\hline & $\begin{array}{c}\text { Full } \\
\text { Sample } \\
(\mathbf{n}=\mathbf{1 , 2 0 0})\end{array}$ & $\begin{array}{l}\text { Chinese } \\
(n=300)\end{array}$ & $\begin{array}{c}\text { South } \\
\text { Asian } \\
(\mathbf{n}=\mathbf{3 5 0})\end{array}$ & $\begin{array}{c}\text { Vietnamese } \\
(n=150)\end{array}$ & $\begin{array}{r}\text { Filipino } \\
(n=100)\end{array}$ & $\begin{array}{r}\text { Other } \\
(\mathrm{n}=300)\end{array}$ \\
\hline \multicolumn{7}{|l|}{$\begin{array}{l}\text { Weight Status Change, Kindergarten to } \\
\text { Second Grade }\end{array}$} \\
\hline Consistently healthy weight $(\%)$ & 72.3 & 77.0 & 70.9 & 71.9 & 62.9 & 72.9 \\
\hline Consistently overweight/obese (\%) & 16.5 & 11.2 & 17.9 & 16.2 & 24.8 & 17.1 \\
\hline Unhealthy weight change $(\%)$ & 7.8 & 6.8 & 8.2 & 6.6 & 9.6 & 8.1 \\
\hline Healthy weight change (\%) & 3.4 & 5.0 & 2.9 & 5.3 & 2.7 & 1.9 \\
\hline $\begin{array}{l}\text { Months elapsed between measurements } \\
\text { (mean (SD)) }\end{array}$ & $24.0(1.0)$ & 23.9 & 24.1 & 23.9 & 24.0 & 24.0 \\
\hline \multicolumn{7}{|l|}{ Demographic Measures } \\
\hline Male child (\%) & 48.0 & 51.1 & 43.3 & 46.0 & 53.1 & 49.8 \\
\hline $\begin{array}{l}\text { Child's age in second grade, in months } \\
\text { (mean) }\end{array}$ & $95.9(4.2)$ & 95.6 & 95.7 & 95.7 & 97.2 & 95.9 \\
\hline \multicolumn{7}{|l|}{ Household/SES Measures } \\
\hline Mother's age, in years (mean (SD)) & $37.4(4.8)$ & 37.0 & 36.9 & 37.3 & 39.1 & 37.9 \\
\hline Siblings in household (mean (SD)) & $1.1(0.9)$ & 0.9 & 1.1 & 1.3 & 1.1 & 1.3 \\
\hline Two biological parents $(\%)$ & 92.2 & 91.6 & 97.5 & 87.9 & 91.0 & 89.5 \\
\hline Mother with $\geq$ high school degree $(\%)$ & 68.7 & 54.2 & 84.0 & 47.4 & 83.5 & 70.9 \\
\hline \multicolumn{7}{|l|}{ Income-to-poverty ratio } \\
\hline$>200 \%$ of FPL $(\%)$ & 58.1 & 43.3 & 75.2 & 39.5 & 71.7 & 57.8 \\
\hline $100-200 \%$ of FPL (\%) & 21.2 & 27.0 & 14.7 & 28.8 & 17.9 & 20.2 \\
\hline$<100 \%$ of FPL $(\%)$ & 20.7 & 29.6 & 10.1 & 31.7 & 10.4 & 22.0 \\
\hline \multicolumn{7}{|l|}{ Mother's Acculturation Measures } \\
\hline $\begin{array}{l}\text { English proficiency, range: 4-16 (mean } \\
(\mathrm{SD}))\end{array}$ & $12.7(3.2)$ & 10.9 & 13.7 & 11.2 & 14.3 & 13.2 \\
\hline Percentage of life spent in U.S. (mean (SD)) & $40.8(22)$ & 38.2 & 35.9 & 43.7 & 37.9 & 47.5 \\
\hline
\end{tabular}

Note: FPL, federal poverty level; SD, standard deviation. 
Table 2. Multinomial logistic regression models predicting weight change categories from kindergarten to second grade, $\mathrm{n}=1,200$ Asian-American children of foreign-born mothers, ECLS-K:2011

\begin{tabular}{|c|c|c|c|c|c|c|c|c|c|}
\hline & \multicolumn{3}{|c|}{ "Consistently Overweight/Obese" } & \multicolumn{3}{|c|}{ "Unhealthy Weight Change" } & \multicolumn{3}{|c|}{ "Healthy Weight Change" } \\
\hline & Model 1a & Model 2a & Model 3a & Model 1b & Model 2b & Model 3b & Model 1c & Model 2c & Model 3c \\
\hline & OR $(95 \%$ CI $)$ & OR $(95 \% \mathrm{CI})$ & OR $(95 \%$ CI $)$ & OR $(95 \%$ CI $)$ & OR $(95 \% \mathrm{CI})$ & OR $(95 \%$ CI $)$ & OR $(95 \%$ CI $)$ & OR $(95 \% \mathrm{CI})$ & OR $(95 \% \mathrm{CI})$ \\
\hline \multicolumn{10}{|l|}{ Demographic Measures } \\
\hline \multicolumn{10}{|l|}{ Ethnicity (ref: Chinese) } \\
\hline South Asian & $1.96(1.03-3.71)$ & $1.71(0.93-3.16)$ & $1.73(0.95-3.17)$ & $1.47(0.74-2.93)$ & $1.89(0.93-3.86)$ & $1.93(0.94-3.93)$ & $0.74(0.29-1.88)$ & $1.10(0.42-2.88)$ & $1.12(0.43-2.93)$ \\
\hline Vietnamese & $1.56(0.80-3.05)$ & $1.62(0.81-3.22)$ & $1.62(0.82-3.23)$ & $1.12(0.39-3.20)$ & $1.18(0.37-3.78)$ & $1.19(0.37-3.78)$ & $1.11(0.41-3.00)$ & $1.15(0.39-3.35)$ & $1.15(0.39-3.38)$ \\
\hline $\begin{array}{l}\text { Other Asian } \\
\text { ethnicity }\end{array}$ & $1.65(0.84-3.24)$ & $1.63(0.80-3.30)$ & $1.62(0.79-3.29)$ & $1.32(0.58-3.01)$ & $1.76(0.73-4.26)$ & $1.76(0.73-4.27)$ & $0.39(0.13-1.14)$ & $0.49(0.16-1.44)$ & $0.49(0.16-1.45)$ \\
\hline $\begin{array}{l}\text { Months between } \\
\text { measurements }\end{array}$ & $1.13(0.92-1.39)$ & $1.10(0.91-1.33)$ & $1.11(0.91-1.34)$ & $1.21(0.92-1.60)$ & $1.30(0.97-1.73)$ & $1.31(1.00-1.74)$ & $1.08(0.75-1.55)$ & $1.19(0.79-1.81)$ & $1.19(0.78-1.82)$ \\
\hline Male child & $1.40(1.00-1.95)$ & $1.36(0.97-1.89)$ & $1.36(0.97-1.90)$ & $1.74(1.08-2.80)$ & $1.81(1.11-2.97)$ & $1.80(1.09-2.97)$ & $2.23(0.97-5.14)$ & $2.32(0.92-5.86)$ & $2.31(0.92-5.83)$ \\
\hline $\begin{array}{l}\text { Child's age in second } \\
\text { grade }\end{array}$ & $1.07(1.02-1.12)$ & $1.07(1.02-1.12)$ & $1.07(1.02-1.12)$ & $1.07(1.01-1.14)$ & $1.07(1.01-1.15)$ & $1.08(1.01-1.15)$ & $0.96(0.88-1.04)$ & $0.97(0.89-1.06)$ & $0.97(0.89-1.06)$ \\
\hline \multicolumn{10}{|l|}{ Household/SES Measures } \\
\hline $\begin{array}{l}\text { Number of siblings in } \\
\text { household }\end{array}$ & $0.98(0.79-1.21)$ & $1.01(0.81-1.26)$ & $1.02(0.81-1.27)$ & $0.88(0.64-1.22)$ & $0.91(0.65-1.27)$ & $0.91(0.65-1.28)$ & $1.12(0.74-1.70)$ & $1.10(0.70-1.73)$ & $1.10(0.70-1.73)$ \\
\hline Two biological parents & $0.89(0.38-2.11)$ & $0.86(0.37-2.00)$ & $0.86(0.37-2.01)$ & $1.00(0.33-2.99)$ & $0.93(0.34-2.58)$ & $0.95(0.33-2.73)$ & $1.18(0.25-5.55)$ & $1.12(0.25-5.01)$ & $1.12(0.25-5.04)$ \\
\hline $\begin{array}{l}\text { Mother with high } \\
\text { school degree }\end{array}$ & $0.86(0.40-1.84)$ & $0.76(0.38-1.53)$ & $4.38(0.85-7.23)$ & $1.60(0.54-4.72)$ & $2.97(0.98-9.00)$ & $4.06(1.08-9.00)$ & $1.06(0.25-4.50)$ & $2.59(0.47-14.23)$ & $4.21(0.14-8.34)$ \\
\hline \multicolumn{10}{|c|}{$\begin{array}{l}\text { Income-to-poverty ratio (ref: >200\% } \\
\text { of FPL) }\end{array}$} \\
\hline $100-200 \%$ of FPL & $1.06(0.51-2.23)$ & $1.12(0.52-2.42)$ & $1.08(0.50-2.35)$ & $1.76(0.81-3.83)$ & $1.44(0.67-3.13)$ & $1.41(0.65-3.06)$ & $1.97(0.73-5.34)$ & $1.37(0.49-3.81)$ & $1.36(0.49-3.75)$ \\
\hline$<100 \%$ of FPL & $1.24(0.40-3.84)$ & $1.30(0.40-4.28)$ & $1.29(0.39-4.24)$ & $1.96(0.60-6.42)$ & $1.41(0.45-4.41)$ & $1.40(0.44-4.46)$ & $1.15(0.11-11.52)$ & $0.72(0.06-7.94)$ & $0.70(0.07-7.43)$ \\
\hline \multicolumn{10}{|c|}{ Mother's Acculturation Measures } \\
\hline English proficiency & & $1.06(0.96-1.17)$ & $1.14(1.02-1.26)$ & & $0.83(0.75-0.92)$ & $0.91(0.75-1.10)$ & & $0.75(0.65-0.86)$ & $0.78(0.62-0.98)$ \\
\hline $\begin{array}{l}\text { Percentage of life } \\
\text { spent in U.S. }\end{array}$ & & $0.28(0.06-1.23)$ & $0.28(0.06-1.27)$ & & $0.52(0.08-3.59)$ & $0.52(0.07-3.70)$ & & $0.68(0.08-3.89)$ & $4.06(0.56-7.84)$ \\
\hline $\begin{array}{l}\text { English proficiency } x \\
\geq \text { high school degree }\end{array}$ & & & $0.87(0.76-0.99)$ & & & $0.86(0.66-1.13)$ & & & $0.93(0.70-1.24)$ \\
\hline
\end{tabular}

Note: FPL, federal poverty level; OR, odds ratios. All ORs represent the odds of being in a weight change category relative to being in the "consistently healthy weight" group. 
Figure 1. Predicted probabilities of weight change by English proficiency and mother's education, $n=1,200$ Asian-American children of foreign-born mothers, ECLS-K:2011

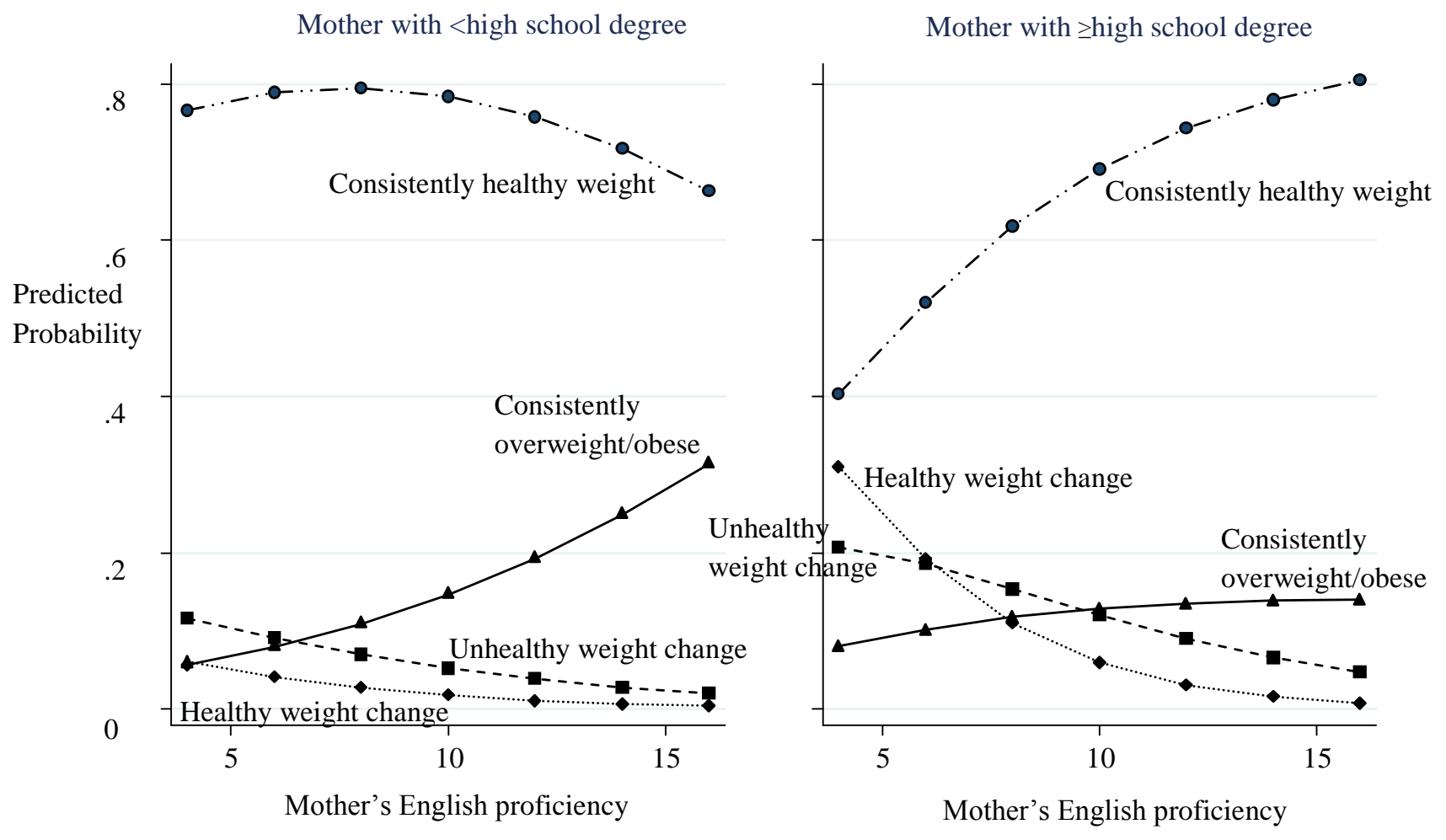

